\title{
The development of an online decision aid to support persons having a genetic predisposition to cancer and their partners during reproductive decision-making: a usability and pilot study
}

\author{
Kelly Reumkens $s^{1,2}$. Marly H. E. Tummers ${ }^{1,2}$. Joyce J. G. Gietel-Habets ${ }^{1,2} \cdot$ Sander M. J. van Kuijk ${ }^{3} \cdot$ Cora M. Aalfs $^{4}$. \\ Christi J. van Asperen ${ }^{5} \cdot$ Margreet G. E. M. Ausems $^{6} \cdot$ Margriet Collée $^{7}$. Charlotte J. Dommering ${ }^{8} \cdot$ C. Marleen Kets $^{9}$. \\ Lizet E. van der Kolk ${ }^{10}$. Jan C. Oosterwijk ${ }^{11}$. Vivianne C. G. Tjan-Heijnen ${ }^{2,12} \cdot$ Trudy van der Weijden $^{13,14}$. \\ Christine E. M. de Die-Smulders ${ }^{1,2}$. Liesbeth A. D. M. van Osch ${ }^{1,13,15}$
}

Published online: 30 May 2018

(c) The Author(s) 2018

\begin{abstract}
An online decision aid to support persons having a genetic predisposition to cancer and their partners during reproductive decision-making was developed. A two-phase usability test was conducted among 12 couples $(\mathrm{N}=22 ; 2$ persons participated without their partner) at risk for hereditary cancer and 15 health care providers. Couples and health care providers expressed similar suggestions for improvements, and evaluated the modified decision aid as acceptable, easy to use, and comprehensible. The final decision aid was pilot tested $(\mathrm{N}=16)$ with paired sample t tests comparing main outcomes (decisional conflict, knowledge, realistic expectations regarding the reproductive options and decision self-efficacy) before (T0), immediately (T1) and 2 weeks after (T2) use of the decision aid. Pilot testing indicated decreased decisional conflict scores, increased knowledge, and improved realistic expectations regarding the reproductive options, at T1 and T2. No effect was found for couples' decision self-efficacy. The positive findings during usability testing were thus reflected in the pilot study. The decision aid will be further evaluated in a nationwide pretest-posttest study to facilitate implementation in the onco-genetic counselling setting. Ultimately, it is expected that the decision aid will enable end-users to make an informed decision.
\end{abstract}

Keywords Reproductive decision-making · Counselling · Decision aid · Hereditary cancer · Informed decision-making · Oncology $\cdot$ Patient education

Kelly Reumkens

Kelly.reumkens@mumc.nl

1 Department of Clinical Genetics, Maastricht University Medical Centre+, Postbox 5800, 6202 AZ Maastricht, The Netherlands

2 GROW School for Oncology and Developmental Biology, Maastricht University Medical Centre+, Maastricht, The Netherlands

3 Department of Clinical Epidemiology and Medical Technology Assessment, Maastricht University Medical Centre+, Maastricht, The Netherlands

4 Department of Clinical Genetics, Academic Medical Centre, Amsterdam, The Netherlands

5 Department of Clinical Genetics, Leiden University Medical Center, Leiden, The Netherlands

6 Division of Biomedical Genetics, Department of Genetics, University Medical Center Utrecht, Utrecht, the Netherlands

7 Department of Clinical Genetics, Erasmus University Medical Center, Rotterdam, The Netherlands
8 Department of Clinical Genetics, VU University Hospital, Amsterdam, The Netherlands

9 Department of Human Genetics, Radboud University Medical Center Nijmegen, Nijmegen, the Netherlands

10 Family Cancer Clinic, Netherlands Cancer Institute, Amsterdam, The Netherlands

11 Department of Genetics, Groningen University Medical Center, University of Groningen, Groningen, the Netherlands

12 Department of Medical Oncology, Maastricht University Medical Centre+, Maastricht, The Netherlands

13 School CAPHRI Care and Public Health Research Institute, Maastricht University Medical Centre+, Maastricht, The Netherlands

14 Department of Family Medicine, Maastricht University Medical Centre+, Maastricht, The Netherlands

15 Department of Health Promotion, Maastricht University Medical Centre+, Maastricht, The Netherlands 


\section{Introduction}

A predisposition for hereditary cancer is usually autosomal dominant, implying that there is a 50\% risk of transmitting the mutation to offspring. Transmission of a predisposition for hereditary cancer to offspring means passing on a generally highly increased risk of developing cancer. For the relatively frequent breast cancer gene mutations in $B R C A 1$ or $B R C A 2$ this implies risks of $27-57 \%$ and $6-40 \%$ of developing breast respectively ovarian cancer by the age of $70[1,2]$. This knowledge may evoke challenging reproductive decision-making processes among persons having a genetic predisposition to cancer and their partners [3-6]. Couples with a predisposition for hereditary cancer who want a genetically related child can opt for natural conception without genetic testing, accepting the risk of passing on the predisposition for cancer to a child, or they could opt for prenatal diagnosis (PND) assuming the intention to terminate the pregnancy if the fetus has the mutation [7], or for preimplantation genetic diagnosis (PGD), to prevent transmission of the mutation to their offspring. PGD involves a multi-stage diagnostic process in which embryos are examined for the presence of the familial mutation before pregnancy is established [7]. Annually approximately 60 couples with a predisposition for hereditary cancer start a PGD procedure in the Netherlands [8], a number that has been steadily increasing since its introduction 10 years ago. In 2016, a total of 40 couples with a predisposition for hereditary breast and ovarian cancer $(H B O C)$ started a PGD procedure and seven couples with familial adenomatous polyposis $(F A P)$. The uptake of PND for hereditary cancer is relatively low $(<2 \%)$ with up till 2013 only a total of six couples with $H B O C$ performed PND $(<0.2 \%)$ and a total of six couples with FAP $(1.6 \%)$ [9]. Although awareness of PGD (66\%) and PND (61\%) are similar, the acceptability of PGD $(80 \%)$ is notably higher compared to PND (26\%) [10].

The decision regarding which reproductive option to choose is highly preference-sensitive. Research has shown that persons having a genetic predisposition to cancer and their partners may experience the reproductive decisionmaking process as complex [6,11-13]. A recent study among couples with $H B O C$, showed that $43 \%$ experienced reproductive decision-making as (very) difficult [13]. Feelings of uncertainty and guilt may be experienced, particularly among couples who opt for natural conception without genetic testing [5]. In deliberating the reproductive options, couples consider personal values and (dis) advantages of all options, which can be categorized into physical (e.g. physical burden of IVF treatment necessary for PGD), psychological (e.g. loss of romance regarding pregnancy), social (e.g. eliminate mutation in family line), ethical (e.g. moral duty to protect the child) and practical considerations (e.g. frequent hospital appointments) [5].

The decision regarding which reproductive option to pursue should ideally involve an informed decision-making process by an educated and empowered couple. In order to promote informed decision-making, decisional support strategies can be effective. Compared to usual care interventions, decision aids have been found to improve people's knowledge regarding their options, reduce decisional conflict, and decrease the proportion of people remaining undecided [13-16]. Incorporating a patient decision aid in reproductive counselling can therefore be helpful in supporting persons having a genetic predisposition to cancer and their partners in making their reproductive decision $[5,17]$.

The present report is part of a project on the development and implementation of an online decision aid. Firstly, we conducted a needs assessment study regarding the preferences and needs of couples and health care providers regarding the decision aid [18]. We integrated the results of the needs assessment study with knowledge on reproductive decisional motives and considerations and designed a concept version of the decision aid [18]. Its user friendliness, strengths and limitations were assessed during usability testing and some modifications were made. Subsequently, the final decision aid was pilot tested. We report on the results of the usability testing and the preliminary results regarding the effectiveness of the decision aid, generates during beta testing (i.e. end-user testing) by means of a pilot study [19].

\section{Methods}

\section{Developmental process and content of the decision aid}

The decision aid was developed according to the International Patient Decision Aids Standards [20] in collaboration with a steering group including health care providers (e.g. clinical geneticists, and social workers), experts in health communication and medical decision-making, psychologists and persons having a genetic predisposition to cancer and their partners who are planning to have children. Our needs assessment study showed many similarities between the expressed preferences and needs of both couples and health care providers concerning the content, barriers and facilitating factors regarding the use of the decision aid, and its implementation [18]. The prototype of the decision aid contained:

1. Information about the risk of transmitting the mutation to offspring.

2. Information about couples' options to have genetically related child(ren) (natural conception without genetic 
testing, PND and PGD) with the aim to increase knowledge. In the needs assessment study, participants agreed upon natural conception without genetic testing, PND and PGD as main reproductive options to be included in the decision aid [18]. Adoption and use of donor gametes are mentioned in the decision aid to make couples aware of the existence of these options. However, as most couples pursue their wish to have genetically related child(ren) [21], these options were not included further.

3. Probabilities of different outcomes and the burden of the treatment of reproductive options (e.g. risk of miscarriage after PND, likelihood of pregnancy with PGD) to increase participants' accuracy of risk comprehension. Based on current recommendations [22] and the preferences of end-users, probabilities were presented in multiple suitable formats using text and videos (e.g. verbal, and population diagrams).

4. A summary table of important features of each reproductive option to facilitate comparison.

5. Values clarification exercises (VCE) [23]. Participants were presented with 18 statements representing values and motives considered important for reproductive decision-making [5]. Participants were asked to rate personal agreement of each statement on a scale from 1 (disagree) to 6 (agree). By linking login codes, an automated combined overview of both partners' input could be generated to facilitate communication about agreements and possible discrepancies.

6. A question prompt sheet, providing examples of questions and requests for additional information and space for own questions, to facilitate discussion with health professionals and others.

7. Information regarding the scientific resources used to underpin the decision aid content, information on the development team (including 'conflicts of interest COI'), funding resources and contact information.

\section{Usability testing}

Minor textual revisions were made after review of the prototype decision aid by the steering group. Subsequently, a two-phase usability test with couples and health care providers was conducted. After the first phase the decision aid was adapted based on provided feedback. To make final modifications, a second usability phase was conducted.

\section{Participants and recruitment}

Dutch couples who consider PGD are referred to the Clinical Genetics Department of the Maastricht University Medical Centre (Maastricht UMC+) for an once only informative consultation. The couples are registered in a database. Eligible participants for the usability test were selected from this database. Couples were eligible for participation if one partner had a confirmed mutation for a hereditary cancer syndrome for which PND and PGD are available in the Netherlands, if they had made a reproductive decision (as indicated in medical records), if both partners were 18 years or older, had sufficient knowledge of the Dutch language, and if they had ample experience with the use of computers and the Internet. Although participation of both partners was encouraged, participation of one partner (regardless of being carrier) was allowed. Couples who provided written informed consent for participation were contacted by telephone to schedule an appointment at the hospital, or, if preferred, at the couple's home.

Furthermore, two representatives of each of the nine Clinical Genetics Departments in the Netherlands, who were directly involved in the counseling and care of end-users (e.g. clinical geneticists and gynecological oncologists) were invited to participate $(\mathrm{N}=18)$. Appointments were scheduled at convenient workplaces.

\section{Procedures}

Usability testing was conducted using a mixed methods design (i.e. qualitative and quantitative) in between March and June 2016. First, couples and health care providers were asked to fill in a brief questionnaire. Age, gender, educational level, carrier status, type of cancer, and experience with the use of computers and the Internet were assessed for couples. Health care providers completed questions concerning their professional perspectives regarding the feasibility of implementing the decision aid. Subsequently, participants were invited to an online 'cognitive walkthrough' of the decision aid in presence of the researcher. They were asked to think aloud and to express freely their opinion regarding its content, functionalities, format and layout [24]. The researchers occasionally asked predetermined questions. 'Thinking aloud' sessions were followed by interviews. The content of the semi-structured topic guides for the interviews focused on the perceived comprehensibility, usability, efficiency and acceptability of the decision aid and were largely similar for the couples and the health care providers. At the end of the interviews, couples were asked to evaluate the decision aid with regard to content, lay-out and usability on a scale of 1-10 and to complete the System Usability Scale (SUS) for the subjective assessment of usability [25-27]. Couples received 15 euros in vouchers and their travel expenses were reimbursed. Health care providers were asked to evaluate the decision aid in terms of quality, completeness, lay-out and usability on a scale of 1-10 with higher scores indicating better usability. 


\section{Data analysis}

Qualitative data derived from the audiotaped 'thinking aloud' sessions and the interviews were transcribed verbatim. Open coding (developing categories of information) and axial coding (exploring the relationship of categories) was performed independently by two researchers (K.R. and M.T.) to derive and categorize main issues. Data from the demographic questionnaire and SUS were analysed by means of descriptive statistics and quantified as mean and standard deviation or absolute number and percentage, using SPSS version 23.

\section{Pilot study}

\section{Participants and recruitment}

Health care providers of all Clinical Genetics Departments in the Netherlands recruited eligible couples during or after oncogenetic consultation. The same inclusion criteria were used as for usability testing, except that couples had not yet made a reproductive decision. Couples were eligible if they expressed the wish to have children within 5 years and have not yet made a definitive decision regarding their preferred reproductive option. Although participation of both partners was encouraged, participation of one partner was allowed.

\section{Procedures and instrumentation}

Adaptation of feedback provided during usability testing resulted in the final decision aid. It was pilot tested from November 2016 to January 2017. Eligible couples were provided with an information brochure, to introduce the study together with a link to an online registration page. After registration, participants received online information about the study and an online informed consent form. After providing consent, participants were directed to an online (baseline) questionnaire (T0) and received a personal login code for the decision aid. Duration of visits and page visits were monitored. Immediately after use of the decision aid, participants were directed to the second online questionnaire (T1). Two weeks after baseline, participants were asked by e-mail to complete the last questionnaire (T2). Participants who did not complete the questionnaire received a reminder by e-mail. Questionnaires were completed separately by both partners. After completing all questionnaires, participants received 15 euros in vouchers.

A demographic questionnaire assessed gender, age, educational level, carrier status, type of cancer, and personal history of cancer at $\mathrm{T} 0$. Less than primary, primary and lower secondary education was considered as low education levels. Upper secondary and post-secondary non-tertiary education was considered as middle education levels. Tertiary education was considered as a high education level. In addition, participants' reproductive history was assessed. The primary outcome measure, i.e. participants' level of decisional conflict, was assessed by the Decisional Conflict Scale at T0, T1 and T2. The questionnaire contains 16 items, each scored on a 5-point Likert scale ranging from 0 (strongly agree) to 4 (strongly disagree). Total scores range from 0 (no decisional conflict) to 100 (extremely high decisional conflict) [28]. Participants' current knowledge of the three reproductive options was assessed by 15 closed-ended questions (true/false/not sure) at T0, T1 and T2, see Table 1 [10]. Three questions measured participants' knowledge of natural conception without genetic testing (e.g. 'when opting for natural conception, there is a $50 \%$ risk of transmitting the mutation to offspring'), five questions measured knowledge of PND (e.g. 'prenatal diagnosis takes place during pregnancy') and seven questions measured knowledge of PGD (e.g. 'In vitro fertilization (IVF) is necessary to perform PGD'). One point was provided for each correctly answered question, which could lead to a maximum score of 15. Realistic expectations regarding the three reproductive options were assessed by three questions at T0, T1 and T2 (i.e. "what is the extra risk of miscarriage due to PND?", "what is the chance of pregnancy after one IVF treatment with PGD?", "what is the risk of complications with PGD?"). These questions contained 8-11 response options. One point was provided for each correctly answered question, which could lead to a maximum score of three [29]. Participants' decision self-efficacy was assessed by the Decision Self-Efficacy Scale at T0, T1 and T2. The questionnaire contains 11 items, each scored on a 5-point Likert scale ranging from 0 (not at all confident) to 4 (very confident). Total scores range from 0 (extremely low self-efficacy) to 100 (extremely high self-efficacy) [30].

\section{Data analysis}

To test for intra-couple correlation, we compared two models for testing the difference in the main outcome (decisional conflict); one linear mixed-effects model in which clustering within couples was corrected for, and one model without correction. Both models yielded similar results, and a likelihood-ratio test showed that correction did not lead to a better fit (likelihood ratio $=0.60$, $\mathrm{p}=0.44$ ). Therefore, all participants can be analyzed as separate individuals and we chose to report the simpler model without correction for clustering and used paired sample $t$ tests to compute differences between the first and subsequent measurements. P-values of $<0.05$ were considered to indicate statistical significance. 
Table 1 Knowledge of the three reproductive options (pilot study)

\begin{tabular}{|c|c|}
\hline No. & Item \\
\hline & Natural conception without genetic testing \\
\hline 1 & When opting for natural conception, there is a $50 \%$ risk of transmitting the mutation to offspring $(\mathrm{T})$ \\
\hline 2 & $\begin{array}{l}\text { When opting for natural conception, besides standard procedures, there will be no extra examinations per- } \\
\text { formed during pregnancy }(\mathrm{T})\end{array}$ \\
\hline \multirow[t]{2}{*}{3} & $\begin{array}{l}\text { When opting for natural conception, during delivery it is already clear whether your child has the mutation } \\
\text { (F) }\end{array}$ \\
\hline & Prenatal diagnosis \\
\hline 4 & Prenatal diagnosis takes place during pregnancy $(\mathrm{T})$ \\
\hline 5 & When opting for prenatal diagnosis, you and your partner can naturally conceive $(\mathrm{T})$ \\
\hline 6 & Results of prenatal diagnosis will always follow within 1 week $(F)$ \\
\hline 7 & Prenatal diagnosis is possible from 6 weeks of pregnancy upon $(\mathrm{F})$ \\
\hline \multirow[t]{2}{*}{8} & Prenatal diagnosis is possible in most of the medical centers in the Netherlands $(\mathrm{T})$ \\
\hline & PGD \\
\hline 9 & In vitro fertilization (IVF) is necessary to perform PGD (T) \\
\hline 10 & PGD is possible in every hospital in the Netherlands $(F)$ \\
\hline 11 & For PGD, cooperation of family members is a prerequisite $(\mathrm{T})$ \\
\hline 12 & Hormone-use by the woman is necessary for a PGD treatment $(\mathrm{T})$ \\
\hline 13 & PGD takes place before the woman is pregnant $(\mathrm{T})$ \\
\hline 14 & A PGD treatment takes at least 6 months $(\mathrm{T})$ \\
\hline 15 & In the Netherlands, a woman's maximum age for PGD is $45(\mathrm{~F})$ \\
\hline
\end{tabular}

Total score range $0-15$

\section{Compliance with ethical standards}

This study was approved by the medical ethics committee of Maastricht UMC+ (METC 14-5-089) and registered in the Dutch Trial Register (NTR5467). The authors declare that they have no conflict of interest. All procedures performed in this study were in accordance with the ethical standards of the medical ethics committee of Maastricht University Medical Centre and have been performed in accordance with the ethical standards as laid down in the 1964 Declaration of Helsinki and its later amendments. Informed consent was obtained from all patients included in this study.

\section{Results}

\section{Usability testing}

\section{Couples' characteristics}

Thirty-nine couples who had reproductive counseling for hereditary cancer between 2013 and 2015, were invited for participation by mail. Twelve couples provided written informed consent $(\mathrm{N}=22 ; 2$ persons participated without their partner), and participated in usability testing (response rate $30.8 \%$ ). Main reasons for non-participation were a lack of time and not wanting to relive the psychological burden associated with reproductive decision-making. The mean age was 34.5 years for males $(\mathrm{SD}=4.5)$ and 29.9 years $(\mathrm{SD}=3.7)$ for females. Most participants were highly educated (64\%), a minority had lower education levels (14\%) and $23 \%$ had an average education level. The types of cancer concerned hereditary breast and ovarian cancer $(\mathrm{N}=6)$, familial adenomatous polyposis $(\mathrm{N}=2)$, Lynch syndrome $(\mathrm{N}=3)$ and multiple endocrine neoplasia $(\mathrm{N}=1)$.

\section{Usability results couples}

During the first phase of the usability test, three couples and one female participant without partner ( $\mathrm{N}=7$ persons) participated. A frequently expressed concern during the 'think aloud' sessions was the amount of scrolling needed to read all provided information. Other suggestions mainly pertained to textual improvements and adaptations to further improve lay-out (e.g. change the order of information and a change of colors). The average duration of the sessions was 71 min (range 60-80). Seven couples and one female participant without partner $(\mathrm{N}=15$ persons $)$ participated in the second phase of usability testing to make final modifications. In general, couples appreciated the lay-out and stated that information in the decision aid was clear and comprehensible. Most couples indicated that they would have used the decision aid, if it had been available at the time of reproductive decision-making, and stated that all functions included 
in the decision aid were well integrated (Table 2). Couples generally agreed that the decision aid was not unnecessarily complex (Table 2). With a mean SUS score (range 0-100) of 91.33 ( $\mathrm{SD}=7.61)$, the decision aid's usability was considered high. Couples graded the decision aid on a scale of $1-10$ with a mean of $8.5(\mathrm{SD}=0.5)$ for the content, a mean of $8.3(\mathrm{SD}=0.8)$ for lay-out and a mean of $8.0(\mathrm{SD}=0.9)$ for usability.

\section{Health care providers' characteristics}

Fifteen health care providers participated (response rate $83.3 \%$ ) in the 'think aloud' sessions and individual interviews ( 1 male and 14 females). The mean age for males was 61 years and mean age for females was 43.5 years $(\mathrm{SD}=6.7)$. These health care providers were clinical geneticists $(\mathrm{N}=6)$, gynecological oncologists $(\mathrm{N}=3)$, genetic counselors $(\mathrm{N}=2)$, social worker $(\mathrm{N}=1)$, medical oncologists $(\mathrm{N}=2)$ and an ophthalmologist $(\mathrm{N}=1$; involved in the care and counseling of persons with a predisposition for retinoblastoma and their partners). The majority had more than 5 years of work experience in the area of oncogenetic counseling and $80 \%$ had no or limited experience with the use of decision aids.

\section{Usability results health care providers}

The average duration of the sessions was 59 min (range 15-80). Similar to couples, health care providers highly appreciated the lay-out of the decision aid, although during 'think aloud' sessions the use of more subtle colors was suggested. Several textual suggestions (e.g. avoidance of medical/technical terms) and suggestions to change the order of information were provided. The different forms of information provision (e.g. written and video-based) and the (VCE) were appreciated. To promote (continued) implementation, it was suggested to include a link to the decision aid in the standard report couples receive after consultation. The format of the final decision aid was considered as acceptable, easy to use and comprehensible. Health care providers graded the decision aid on a scale of $1-10$ with a mean score of $8.2(\mathrm{SD}=0.5)$ for quality, a mean of $8.5(\mathrm{SD}=0.5)$ for completeness, a mean of 7.9 $(\mathrm{SD}=0.4)$ for lay-out and a mean of $7.3(\mathrm{SD}=0.7)$ for usability. The moderate mean usability score of 7.3 was likely due to the order in which information was presented in the decision aid. Changes were made to the decision aid based on feedback provided.

\section{Pilot study}

\section{Participants' characteristics}

Eight couples $(\mathrm{N}=16)$ participated in the pilot study. A response rate could not be estimated because the exact number of patients invited by each Clinical Genetics Department is unknown due to the large number of counselors recruiting. Table 3 shows an overview of the sample characteristics. Participants' average age was 32.4 years for males $(\mathrm{SD}=4.6)$ and 29.1 years $(\mathrm{SD}=4.3)$ for females. None of the participants had a low education level. Of the participants, $68.8 \%$ already had a preferred option in mind at baseline, $31.2 \%$ did not. None of the participants changed their mind from T0-T1 and from T0-T2. The mean time spent using the decision aid was 27 min (range 2-104 min) and participants viewed on average 20 out of 36 pages. $69 \%$ viewed at least 25 pages with pages on contact information and disclaimer being the least viewed.
Table 2 System usability scale results (usability study)

\begin{tabular}{llr}
\hline No. & Item & $\begin{array}{l}\text { N=15 } \\
\text { Mean (SD) }\end{array}$ \\
\hline 1 & I think that I would like to use the DA frequently & $3.07(1.16)$ \\
2 & I found the DA unnecessarily complex & $0.20(0.78)$ \\
3 & I thought the DA was easy to use & $3.53(0.74)$ \\
4 & I think that I would need technical support to be able to use the DA & $0.00(0.00)$ \\
5 & I found the various functions included in the DA well integrated & $3.47(0.64)$ \\
6 & I thought there was too much inconsistency in the DA & $0.40(1.06)$ \\
7 & I would imagine that people would learn to use the DA very quickly & $3.53(0.52)$ \\
8 & I found the DA very cumbersome to use & $0.07(0.26)$ \\
9 & I felt very confident using the DA & $3.73(0.46)$ \\
10 & I needed to learn a lot before I could get going with the DA & $0.13(0.35)$ \\
Total score & & $91.33(7.61)$ \\
\hline
\end{tabular}

Total score range $0-100$; higher scores indicate higher perceived usability

$D A$ decision aid 
Table 3 Sample characteristics (pilot study)

\begin{tabular}{|c|c|c|}
\hline Sample characteristics $(\mathrm{n}=16)$ & $\mathrm{N}$ & $\%$ \\
\hline \multicolumn{3}{|l|}{ Gender } \\
\hline Male (M) & 8 & 50.0 \\
\hline Female (F) & 8 & 50.0 \\
\hline \multicolumn{3}{|l|}{ Age (years) } \\
\hline Male & $32.4(\mathrm{SD}=4.6)$ & \\
\hline Female & $29.1(\mathrm{SD}=4.3)$ & \\
\hline \multicolumn{3}{|l|}{ Education } \\
\hline Middle & 7 & 43.8 \\
\hline High & 9 & 56.2 \\
\hline \multicolumn{3}{|l|}{ Carrier status } \\
\hline Male & 2 & 12.5 \\
\hline Female & 6 & 87.5 \\
\hline \multicolumn{3}{|l|}{ Syndrome } \\
\hline Hereditary breast and ovarian cancer & $7(5 \mathrm{~F} / 2 \mathrm{M})$ & 87.5 \\
\hline Lynch syndrome & $1(\mathrm{~F})$ & 12.5 \\
\hline \multicolumn{3}{|l|}{ Have (had) cancer } \\
\hline Yes & 4 & 25.0 \\
\hline No & 12 & 75.0 \\
\hline \multicolumn{3}{|l|}{ Reproductive history } \\
\hline \multicolumn{3}{|l|}{ Children } \\
\hline Yes & 2 & 12.5 \\
\hline No & 14 & 87.5 \\
\hline \multicolumn{3}{|l|}{ Planning to have children } \\
\hline Currently pregnant & 2 & 12.5 \\
\hline Planning to have children within 5 years & 14 & 87.5 \\
\hline \multicolumn{3}{|l|}{ Preferred reproductive option in mind at $\mathrm{T} 0$} \\
\hline Yes & 11 & 68.8 \\
\hline No & 5 & 31.2 \\
\hline
\end{tabular}

\section{Preliminary effects of decision aid}

All 16 participants completed $\mathrm{T} 0$ and $\mathrm{T} 1$ and 15 participants completed T2. As shown in Table 4, mean decisional conflict scores (range 0-100) decreased from a mean of 27.6 $(\mathrm{SD}=19.3)$ at baseline, to $11.8(\mathrm{SD}=15.3)$ at $\mathrm{T} 1(\mathrm{t}=5.73$; $\mathrm{p}<0.001 ; \mathrm{ES}=1.73)$ and $8.3(\mathrm{SD}=6.4)$ at $\mathrm{T} 2(\mathrm{t}=3.37$; $\mathrm{p}=0.01 ; \mathrm{ES}=1.12$ ). The mean level of knowledge (range $0-15)$ increased from $8.2(\mathrm{SD}=3.5)$ at baseline, to 12.4 $(\mathrm{SD}=3.7)$ at $\mathrm{T} 1(\mathrm{t}=-7.73 ; \mathrm{p}<0.001 ; \mathrm{ES}=-1.93)$ and $12.8(\mathrm{SD}=2.1)$ at $\mathrm{T} 2(\mathrm{t}=-10.05 ; \mathrm{p}<0.001 ; \mathrm{ES}=-2.69)$. Further, realistic expectations regarding the three reproductive options (range 0-3) increased from $0.4(\mathrm{SD}=0.5)$ at baseline, to $1.9(\mathrm{SD}=1.0)$ at $\mathrm{T} 1(\mathrm{t}=-6.45 ; \mathrm{p}<0.001$; $\mathrm{ES}=-0.75)$ and $1.3(\mathrm{SD}=1.0)$ at $\mathrm{T} 2(\mathrm{t}=-4.33 ; \mathrm{p}<0.001$; $\mathrm{ES}=-0.25$ ). Couples' decision self-efficacy (range 0-100) slightly increased but did not significantly change over time from $80.4(\mathrm{SD}=16.9)$ at baseline, to $81.3(\mathrm{SD}=16.0)$ at $\mathrm{T} 1$ $(\mathrm{t}=-0.28 ; \mathrm{p}=0.782 ; \mathrm{ES}=-0.07)$ and $83.9(\mathrm{SD}=19.6)$ at $\mathrm{T} 2(\mathrm{t}=-0.38 ; \mathrm{p}=0.708 ; \mathrm{ES}=-0.10)$.

\section{Discussion}

This study presents the development and preliminary evaluation of an online decision aid that aims to support persons having a genetic predisposition to cancer and their partners during their reproductive decision-making. Previous studies demonstrated that these couples may experience the decision-making process as complex $[6,11,12$, 31]. The decision aid aims to decrease participants' level of decisional conflict, increase participants' knowledge, improve realistic expectations regarding the available reproductive options and increase participants' decision self-efficacy. The high mean score on the SUS indicates that the decision aid meets the needs of the target population. During usability testing, couples and health care providers expressed similar suggestions for improvements. Overall the decision aid was evaluated as acceptable, easy to use, and comprehensible. The positive findings during usability testing were reflected in the preliminary results regarding efficacy of the decision aid, indicated by reduction of couples' decisional conflict levels, increases in knowledge levels and improvement of realistic expectations regarding available reproductive options. This suggests that with use of the decision aid, informed decisionmaking among persons having a genetic predisposition to cancer and their partners during reproductive decisionmaking may be improved. Despite the complexity of the decision, couples' confidence in their ability to make a decision was already high at baseline and did not increase as a result of decision aid use, possibly reflecting a ceiling effect. This may be explained by the finding that 11 out of 16 participants already had a preferred reproductive option in mind at baseline, indicating that couples had already considered the available reproductive options to a certain extent. However, although couples overall felt confident about making a reproductive decision, baseline knowledge levels were relatively low. As a solid knowledge base is regarded as a prerequisite for informed decision-making [32], this finding further emphasizes the need for informational support among our sample.

In order to optimize the impact of the decision aid with regard to decision self-efficacy, the use of modeling techniques may be considered [33], for instance by means of incorporating narrative stories in the decision aid. Previous research, including a needs assessment regarding the current decision aid, indicated that both couples and health care providers advocate the provision of narrative stories during reproductive decision-making [5, 18]. These personal stories detail the experiences of couples with reproductive decision-making and are aimed at providing illustrative examples of others' experiences. Narratives can be useful in overcoming preconceived beliefs and cognitive 
Table 4 Overview of main outcome measures (pilot study)

\begin{tabular}{|c|c|c|c|c|c|c|c|}
\hline \multirow[t]{3}{*}{ Questionnaire $(\mathrm{N}=16)$} & \multicolumn{3}{|c|}{ Means (SD) } & \multicolumn{4}{|c|}{ Paired samples t-test } \\
\hline & \multirow[t]{2}{*}{ T0 } & \multirow[t]{2}{*}{$\mathrm{T} 1$} & \multirow[t]{2}{*}{$\mathrm{T} 2$} & \multicolumn{2}{|l|}{ T0-T1 } & \multicolumn{2}{|l|}{ T0-T2 } \\
\hline & & & & $T$ & $p$ & $T$ & $p$ \\
\hline \multicolumn{8}{|l|}{ Decisional conflict } \\
\hline Total score $(0-100)$ & $\begin{array}{l}27.6 \\
(19.3)\end{array}$ & $\begin{array}{l}11.8 \\
(15.3)\end{array}$ & $\begin{array}{l}8.3 \\
(6.4)\end{array}$ & 5.73 & $<0.001$ & 3.37 & 0.010 \\
\hline Uncertainty & $\begin{array}{l}43.8 \\
(28.5)\end{array}$ & $\begin{array}{l}27.6 \\
(30.4)\end{array}$ & $\begin{array}{l}29.2 \\
(27.7)\end{array}$ & 3.67 & 0.002 & 2.19 & 0.047 \\
\hline Informed & $\begin{array}{l}40.6 \\
(22.5)\end{array}$ & $\begin{array}{l}17.7 \\
(18.5)\end{array}$ & $\begin{array}{l}11.3 \\
(13.7)\end{array}$ & 5.21 & $<0.001$ & 5.97 & $<0.001$ \\
\hline Values clarity & $\begin{array}{l}30.2 \\
(26.2)\end{array}$ & $\begin{array}{l}19.3 \\
(21.9)\end{array}$ & $\begin{array}{l}11.9 \\
(15.6)\end{array}$ & 2.78 & 0.014 & 3.54 & 0.004 \\
\hline Support & $\begin{array}{l}24.0 \\
(16.6)\end{array}$ & $\begin{array}{l}17.7 \\
(18.0)\end{array}$ & $\begin{array}{l}13.7 \\
(14.1)\end{array}$ & 1.60 & 0.131 & 2.65 & 0.020 \\
\hline Effective decision & $\begin{array}{l}17.6 \\
(15.0)\end{array}$ & $\begin{array}{l}8.0 \\
(15.3)\end{array}$ & $\begin{array}{l}5.6 \\
(11.5)\end{array}$ & 4.54 & $<0.001$ & 1.71 & 0.126 \\
\hline \multicolumn{8}{|l|}{ Knowledge } \\
\hline Total score $(0-15)$ & $\begin{array}{l}8.2 \\
(3.5)\end{array}$ & $\begin{array}{l}12.4 \\
(3.7)\end{array}$ & $\begin{array}{l}12.8 \\
(2.1)\end{array}$ & -7.73 & $<0.001$ & -10.05 & $<0.001$ \\
\hline Natural conception $(0-3)$ & $\begin{array}{l}2.0 \\
(1.0)\end{array}$ & $\begin{array}{l}2.3 \\
(0.9)\end{array}$ & $\begin{array}{l}2.5 \\
(0.9)\end{array}$ & -1.78 & 0.096 & -2.45 & 0.028 \\
\hline PND (0-5) & $\begin{array}{l}1.8 \\
(1.7)\end{array}$ & $\begin{array}{l}3.9 \\
(1.4)\end{array}$ & $\begin{array}{l}4.5 \\
(2.0)\end{array}$ & -5.33 & $<0.001$ & -3.96 & $<0.001$ \\
\hline PGD (0-7) & $\begin{array}{l}4.4 \\
(1.8)\end{array}$ & $\begin{array}{l}6.1 \\
(1.9)\end{array}$ & $\begin{array}{l}6.4 \\
(0.9)\end{array}$ & -5.65 & $<0.001$ & -3.67 & 0.003 \\
\hline Realistic expectations (0-3) & $\begin{array}{l}0.4 \\
(0.5)\end{array}$ & $\begin{array}{l}1.9 \\
(1.0)\end{array}$ & $\begin{array}{l}1.3 \\
(1.0)\end{array}$ & -6.45 & $<0.001$ & -4.33 & $<0.001$ \\
\hline Decision self-efficacy $(0-100)$ & $\begin{array}{l}80.4 \\
(16.9)\end{array}$ & $\begin{array}{l}81.3 \\
(16.0)\end{array}$ & $\begin{array}{l}83.9 \\
(19.6)\end{array}$ & -0.28 & 0.782 & -0.38 & 0.708 \\
\hline
\end{tabular}

biases and integrating narratives into healthcare communication is increasingly being recommended [34, 35]. Currently insufficient evidence exists about the effectiveness of narrative stories on informed decision-making and how to incorporate these stories in decision support tools [36, 37]. Future research should explore essential elements of the content of narrative stories and their effectiveness in facilitating decision-making.

A limitation of this study relates to the small sample size and selection bias towards higher educated and possibly higher health literate users which may limit generalizability of the results. Subsequently, the decision aid will be further evaluated in a nation-wide effect study to draw more robust conclusions. Ultimately, it is expected that the decision aid will enable endusers to make an informed decision, which may lessen the negative psychological impact of decision-making on couples' daily life and wellbeing.

\section{Conclusions}

The current findings indicate that the decision aid was well received by both couples and health care providers as reflected in high usability scores and promising preliminary efficacy during the pilot study. The decision aid will be further evaluated in a nationwide pretest-posttest study.

Acknowledgements The work in this study was conducted to fulfill a degree requirement and was funded by the Dutch Cancer Society (Alpe d'HuZes; Grant Number UM2013-6374).

Open Access This article is distributed under the terms of the Creative Commons Attribution 4.0 International License (http://creativeco mmons.org/licenses/by/4.0/), which permits unrestricted use, distribution, and reproduction in any medium, provided you give appropriate credit to the original author(s) and the source, provide a link to the Creative Commons license, and indicate if changes were made. 


\section{References}

1. Chen S, Parmigiani G (2007) Meta-analysis of BRCA1 and BRCA2 penetrance. J Clin Oncol 25:1329-1333

2. Brohet RM, Velthuizen ME, Hogervorst FB, Meijers-Heijboer HE, Seynaeve C, Collée MJ, Verhoef S, Ausems MG, Hoogerbrugge $\mathrm{N}$, van Asperen CJ et al (2014) Breast and ovarian cancer risks in a large series of clinically ascertained families with a high proportion of BRCA1 and BRCA2 Dutch founder mutations. J Med Genet 51:98-107

3. Van Asperen CJ, Van Dijk S, Zoeteweij MW, Timmermans DR, De Bock GH, Meijers-Heijboer EJ, Niermeijer MF, Breuning MH, Kievit J, Otten W (2002) What do women really want to know? Motives for attending familial breast cancer clinics. J Med Genet 39(6):410-414

4. Donnelly LS, Watson M, Moynihan C, Bancroft E, Evans DG, Eeles R, Lavery S, Ormondroyd E (2013) Reproductive decision-making in young female carriers of a BRCA mutation. Hum Reprod 28(4):1006-1012

5. Derks-Smeets I, Gietel-Habets J, Tibben A, Tjan-Heijnen V, Meijer-Hoogeveen M, Geraedts J et al (2014) Decision-making on preimplantation genetic diagnosis and prenatal diagnosis: a challenge for couples with hereditary breast and ovarian cancer. Hum Reprod 5(29):1103-1112

6. Dekeuwer C, Bateman S (2013) Much more than a gene: hereditary breast and ovarian cancer, reproductive choices and family life. Med Health Care Philos 16(2):231-244

7. de Die-Smulders C, de Wert G, Liebaers I, Tibben A, EversKiebooms G (2013) Reproductive options for prospective parents in families with Huntington's disease: clinical, psychological and ethical reflections. Hum Reprod 19(3):304-315. https://doi. org/10.1093/humupd/dms058

8. Annual report PGD in the Netherlands (2016) http://www.pgdne derland.nl

9. Dommering CJ, Henneman L, van der Hout AH, Jonker MA, Tops CMJ, van den Ouweland AMW, van der Luijt RB, Mensenkamp AR, Hogervorst FB, Redeker EJ, de Die-Smulders CE, Moll AC, Meijers-Heijboer H (2017) Uptake of prenatal diagnostic testing for retinoblastoma compared to other hereditary cancer syndromes in the Netherlands. Fam Cancer 16(2):271-277

10. Gietel-Habets JJG, de Die-Smulders CEM, Derks-Smeets IAP, Tibben A, Tjan-Heijnen VCG, van Golde R, Gomez-Garcia E, Kets CM, van Osch LADM (2017) Awareness and attitude regarding reproductive options of persons carrying a BRCA mutation and their partners. Hum Reprod 32(3):588-597

11. Ormondroyd E, Donnelly L, Moynihan C, Savona C, Bancroft E, Evans D et al (2012) Attitudes to reproductive genetic testing in women who had a positive BRCA test before having children: a qualitative analysis. Eur J Hum Genet 20(1):4-10

12. Dommering CJ, van den Heuvel MR, Moll AC, Imhof SM, Meijers-Heijboer H, Henneman L (2010) Reproductive decisionmaking: a qualitative study among couples at increased risk of having a child with retinoblastoma. Clin Genet 78(4):334-341

13. Stacey D, Bennett CL, Barry MJ, Col NF, Eden KB, HolmesRovner M, Llewellyn-Thomas H, Lyddiatt A, Légaré F, Thomson R (2011). Decision aids for people facing health treatment or screening decisions. Cochrane Database Syst Rev. https://doi. org/10.1002/14651858.CD001431

14. O'Connor A, Jacobsen MJ (2003) Workbook on developing and evaluating patient decision aids. Ottawa Health Research Institute

15. Green MJ, Peterson SK, Baker MW et al (2004) Effect of a computer-based decision aid on knowledge, perceptions, and intentions about genetic testing for breast cancer susceptibility a randomized controlled trial. JAMA 292(4):442-452
16. Juraskova I, Butow P, Bonner C, Bell M, Smith AB, Seccombe M et al (2014) Improving decision making about clinical trial participation: a randomized controlled trial of a decision aid for women considering participation in the IBIS-II breast cancer prevention trial. Br J Cancer 111(1):1-7

17. Quinn GP, Vadaparampil ST, Tollin S, Miree CA, Murphy D, Bower B, Silva C (2010) BRCA carriers' thoughts on risk management in relation to preimplantation genetic diagnosis and childbearing: when too many choices are just as difficult as none. Fertil Steril 94(6):2473-2475

18. Reumkens K, van Oudheusden AJG, Gietel-Habets JJG, Tummers MHE, de Die-Smulders CEM, van Osch LADM. (2017) Reproductive decision support: preferences and needs of couples at risk for hereditary cancer and clinical geneticists. J Genet Couns. https ://doi.org/10.1007/s10897-017-0204-6

19. Coulter A, Stilwell D, Kryworuchko J, Mullen PD, Ng CJ, van der Weijden T (2013) A systematic development process for patient decision aids. BMC Med Inform Decis Mak 13(Suppl 2):S2. https ://doi.org/10.1186/1472-6947-13-S2-S2

20. Volk RJ, Llewellyn-Thomas H, Stacey D, Elwyn G (2013) Ten years of the International patient decision aid standards collaboration: evolution of the core dimensions for assessing the quality of patient decision aids. BMC Med Inform Decis Mak 13(2):S1

21. Chan JL, Johnson LNC, Sammel MD et al. (2016). Reproductive decision-making in women with BRCA1/2mutations. J Genet Couns. https://doi.org/10.1007/s10897-016-0035-x

22. Trevena LJ, Zikmund-Fisher BJ, Edwards A, Gaissmaier W, Galesic M, Han PKJ et al (2013) Presenting quantitative information about decision outcomes: a risk communication primer for patient decision aid developers. BMC Med Inform Decis Mak 13(2):S7

23. Fagerlin A, Pignone M, Abhyankar P, Col N, Feldman-Stewart D, Gavaruzzi T, Kryworuchko J, Levin CA, Pieterse AH, Reyna V, Stiggelbout A, Scherer LD, Wills C, Witteman HO (2013) Clarifying values: an updated review. BMC Med Inform Dec Making 13(2):S8

24. Ericsson KA, Simon HA (1984) Protocol analysis: verbal reports as data, (Revised ed.). MIT Press, London

25. Brooke J (1996) SUS: a "quick and dirty" usability scale. In: Jordan PW, Thomas B, Weerdmeester BA, McClelland IL (eds) Usability evaluation in industry. Taylor \& Francis, London, pp 189-194

26. Bangor A, Kortum PT, Miller JT (2008) An empirical evaluation of the system usability scale. Intl J Human-Computer Interact 24:574-594

27. Lewis JR, Sauro J (2009). The factor structure of the system usability scale. Lecture notes in computer science. In: Proceedings of the 1 st international conference on human centered design: held as Part of HCI International; p. 94-103

28. O'Connor AM (1995) Validation of a decisional conflict scale. Med Decis Mak 15(1):25-30

29. O'Connor AM (1995) User manual realistic expectations. http:// www.ohri.ca/decisionaid

30. Bunn H, O'Connor A (1996) Validation of client decisionmaking instruments in the context of psychiatry. Can J Nurs Res 28(3): 13-27

31. Gietel-Habets JJG, de Die-Smulders C, Derks-Smeets IAP, Tibben A, Tjan-Heijnen VCG, van Golde R, Gomez-Garcia E, van Osch LADM (2018). Support needs of couples with hereditary breast and ovarian cancer during reproductive decision-making. Psychooncology. https://doi.org/10.1002/pon.4729

32. Van den Berg M, Timmermans DRM, Ten Kate LP, Van Vugt JMG, Van der Wal G (2006) Informed decision making in the context of prenatal screening. Patient Educ Couns 63(1):110-117

33. Bandura A (1994) Self-efficacy. In: Ramachaudran VS (ed.) Encyclopedia of human behavior, vol 4. Academic Press, New York, 
pp 71-81 (Reprinted in Friedman H (ed.) (1998) Encyclopedia of mental health. Academic Press, San Diego)

34. Hinyard L, Kreuter M (2007). Using narrative communication as a tool for health behavior change: a conceptual, theoretical, and empirical overview. Health Educ Behav 34:777-792

35. Rubin LR, Werner-Lin A, Sagi M, Cholst I, Stern R, Lilienthal D, Hurley K (2014). 'The BRCA Clock is Ticking!': Negotiating medical concerns and reproductive goals in preimplantation genetic diagnosis, Hum Fertil 17(3):159-164
36. Bekker HL, Winterbottom A, Buttow P, Dillard A, FeldmanStewart D, Fowler J et al (2012) Using personal stories. In: Volk $\mathrm{R}$, Llewellyn-Thomas H (eds) Update of the International Patient Decision Aids Standards (IPDAS) Collaboration's Background Document. Chapter E. http://ipdas.ohri.ca/resources.html

37. Bekker HL, Winterbottom AE, Butow P, Dillard AJ, FeldmanStewart D, Fowler FJ et al (2013) Do personal stories make patient decision aids more effective? A critical review of theory and evidence. BMC Med Inform Decis Mak 13(2):S9 